\section{Particulate matter: short-term but high-impact exposure at public gathering in Germany}

\section{Dear editor,}

Particulate matter (PM) air pollution is increasingly regarded as a global health threat $^{1}$ and China in particular is frequently criticised for having problems with haze and air pollution. ${ }^{2}$ A systematic analysis of the global burden of disease in 2010 described a shift of risk factors away from communicable diseases in children towards non-communicable diseases in adults. Ambient PM air pollution was specified as a key, new risk factor in the global disease burden. ${ }^{3}$

While the effects of long-term exposure to PM air pollution have been discussed extensively, the effects of short-term exposure to high concentrations of PM
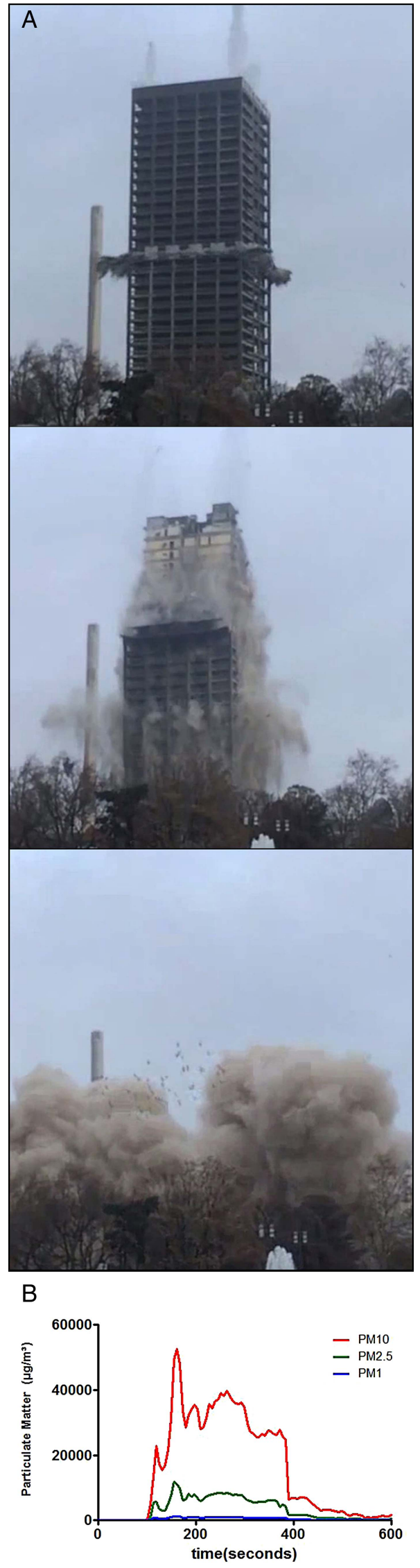

Figure 1 (A) Three pictures of the detonating AFE Tower in Frankfurt am Main, 2 February 2014. (B) The graph documents the concentration of PM10, PM2.5 and PM1 in $\mu \mathrm{g} / \mathrm{m}^{3}$ for several minutes during the collapse of the building. PM, particulate matter. 
are only slowly becoming the focus of public interest and should not be underestimated since there is growing evidence for adverse health effects of short-term exposure to PM2.5. A systematic review and meta-analysis recently published in Thorax on 4 April 2014 is devoted to this issue. ${ }^{4}$ The harmful health effects of short-term high-impact exposure to PM include (among others) several respiratory symptoms and cardiovascular morbidity and mortality. An example of persistent respiratory damage following acute highintensity exposure to PM is the case of a substantial proportion of fire fighters and emergency medical service workers who had never smoked and were acutely exposed to World Trade Centre dust between 11 September and 24 September 2001. They showed large declines in $\mathrm{FEV}_{1}$ in the first year without recovery over the next 6 years. ${ }^{5}$

On 2 February 2014, a 114 m tall skyscraper was detonated in the inner city of Frankfurt am Main. It was the highest building ever brought to implosion in Europe. Spectators were invited to follow this in VIP lounges only $250 \mathrm{~m}$ from the site of detonation. We measured PM10 concentrations as high as $54000 \mu \mathrm{g} / \mathrm{m}^{3}$ and PM2.5 concentrations up to $13000 \mu \mathrm{g} / \mathrm{m}^{3}$ for about $400 \mathrm{~s}$ within the spectator area (figure 1 ).

In the light of this, the abandonment of the plan to blow up five 30-storey Red Road residential blocks in north Glasgow as part of the 2014 Commonwealth Games opening ceremony on 23 Julyofficially for 'safety' reasons-is to be welcomed. In consideration of the known health hazards, building implosions in urban communities should be generally avoided.

\section{Alexander Gerber, Maja Krause, \\ David Groneberg}

Institute of Occupational Medicine, Social Medicine and Environmental Medicine, Goethe-University Frankfurt, Frankfurt am Main, Germany

Correspondence to Dr Alexander Gerber, Institute of Occupational Medicine, Social Medicine and Environmental Medicine, Goethe-University Frankfurt, Theodor-Stern-Kai 7, Frankfurt am Main 60590, Germany; gerber@med.uni-frankfurt.de

Contributors MK performed the measurements; AG wrote the letter; DG conceived the idea and corrected the letter.

\section{Competing interests None.}

Provenance and peer review Not commissioned; internally peer reviewed.

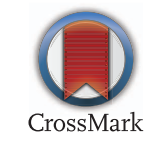

To cite Gerber A, Krause M, Groneberg D. Thorax 2014;69:954-955.

Received 10 April 2014

Revised 25 April 2014

Accepted 29 April 2014

Published Online First 15 May 2014

Thorax 2014;69:954-955.

doi:10.1136/thoraxjnl-2014-205551

\section{REFERENCES}

1 Beelen R, Raaschou-Nielsen O, Stafoggia M, et al. Effects of long-term exposure to air pollution on natural-cause mortality: an analysis of 22 European cohorts within the multicentre ESCAPE project. Lancet 2014:383:785-95.

2 Xu P, Chen Y, Ye X. Haze, air pollution, and health in China. Lancet 2013;382:2067.

3 Lim SS, Vos T, Flaxman AD, et al. A comparative risk assessment of burden of disease and injury attributable to 67 risk factors and risk factor clusters in 21 regions, 1990-2010: a systematic analysis for the Global Burden of Disease Study 2010. Lancet 2012;380:2224-60.

4 Atkinson RW, Kang S, Anderson HR, et al. Epidemiological time series studies of PM2.5 and daily mortality and hospital admissions: a systematic review and meta-analysis. Thorax 2014;69:660-5.

5 Aldrich TK, Gustave J, Hall CB, et al. Lung function in rescue workers at the World Trade Center after 7 years. N Engl I Med 2010;362: 1263-72. 